\title{
AVALIAÇÃO DO ISOTIPO IgG1 e IgG2 POR CITOMETRIA DE FLUXO EM PACIENTES COM LTA
}

\author{
A. M. S. PEREIRA ${ }^{1 *}$, B. C. OLIVEIRA ${ }^{2,}$ A. P. OLIVEIRA ${ }^{2}$ e V. P.HERNANDES ${ }^{2}$ \\ ${ }^{1}$ Universidade Federal Rural de Pernambuco \\ ${ }^{2}$ Centro de Pesquisas Aggeu Magalhães, FIOCRUZ, Recife, Pernambuco, Brazil \\ *E-mail para contato: allanamariasp@gmail.com
}

RESUMO - A atual pesquisa tem como objetivo avaliar, através de citometria de fluxo, a participação da resposta imune humoral no desenvolvimento de lesões cutâneas e na resposta ao tratamento em indivíduos infectados com L. (V.) braziliensis. O ensaio de citometria de fluxo foi realizado a partir da utilização de amostras de soros inativados e formas promastigotas de Leishmania (V.) braziliensis fixadas. Como resultados da padronização dos isotipos IgG1 e IgG2, pôde-se selecionar a diluição 1:400 para o isotipo IgG1 e 1:100 para o isotipo IgG2. Na análise da aplicabilidade do isotipo IgG1 foi constatado que, antes do tratamento, 36,8\% dos pacientes se apresentaram negativos. Os resultados dos pacientes com um ano, dois e cinco anos após o tratamento, apresentaram percentuais de negatividade de $82,3 \% \%, 27,2 \%$ e $87,5 \%$, respectivamente. Diante dos resultados obtidos é possivel sugerir que a citometria de fluxo é aplicável ao diagnóstico da LTA e que a utilização do isotipo IgG1 tem amplas possibilidades para contribuir como um método de diagnóstico mais específico.

Palavras-chave: Leishmania (V.) braziliensis. Imunologia. Citometria. Isotipo.

ABSTRACT: The present project aims to evaluate, through flow cytometry, the participation of the humoral immune response in the development of cutaneous lesions and in response to the treatment in individuals infected with $L$. (V.) braziliensis. The flow cytometry assay was performed using inactivated serum samples and fixed Leishmania (V.) braziliensis promastigote forms. As a result of the standardization of IgG1 and IgG2 isotypes, the 1:400 dilution for IgG1 and 1:100 for IgG2 could be selected. In the analysis of the applicability of IgG1 isotype, it was verified that, before treatment, $36.8 \%$ of the patients were negative. The results of patients with one year, two and five years after treatment showed negative percentages of $82.3 \%, 27.2 \%$ and $87.5 \%$, respectively. In view of the results obtained it is possible to suggest that flow cytometry is applicable to the diagnosis of ATL and that the use of the IgG1 isotype has strong possibilities in contributing as a more specific diagnostic method.

Key words: Leishmania (V.) braziliensis. Immunology. Flow Cytometry. Isotype. 


\section{INTRODUÇÃO}

A Leishmaniose Tegumentar Americana (LTA) é uma patologia considerada emergente e negligenciada, causada por diversas espécies de protozoários parasitas do gênero Leishmania. A Leishmania (V) braziliensis é o agente específico da LTA no Brasil devido ao grande número de casos encontrados em todo o território nacional (CROFT; COOMS, 2003; TIUMAN et al., 2011). Uma das maiores complicações em uma infecção por Leishmania spp. é a capacidade do parasito em desviar e subverter as respostas imunes do hospedeiro (GURUNG; KANNEGANTI, 2015). A resposta imune inata é essencial para a eliminação de patógenos invasores, embora o mecanismo protetor da LTA seja dependente das células T (TRUJILLO et al., 2000; SOUZA et al., 2005).

A análise de anticorpos anti-Leishmania permite avaliar o curso evolutivo da infecção e fornecer dados sobre as características da resposta imune. Perfis e níveis de imunoglobulinas específicas para Leishmania têm sido detectados em pacientes com LTA (DE OLIVEIRA et al., 2013). Pesquisas correlacionam as diversas manifestações clínicas de LTA com as subclasses de IgG (TRUJILLO et al., 2000; REIS, 2007). Nas leishmanioses cutânea e mucocutânea a resposta do tipo Th1 tem sido associada com a presença de isotipos IgG1, IgG2 e IgG3. A resposta do tipo Th2 está vinculada com a presença de IgG4 para a leishmaniose cutânea difusa (SOUZA et al., 2005;).

A citometria de fluxo vem sendo empregada como uma abordagem imunológica para o diagnóstico da LTA. Esta tecnologia promove a análise simultânea de diferentes características físicas de partículas individuais, conforme o fluxo de fluido desloca-se através de um feixe de luz, possibilitando a detecção e análise quantitativa de anticorpos anti-Leishmania, através de marcação simples utilizando anticorpos conjugados diretamente a fluorocromos (MARTINS-FILHO et al., 1995; PEDRAL-SAMPAIO et al., 2016). Esta técnica apresenta diversas vantagens como a quantificação do analito, volume reduzido de amostra, grande reprodutibilidade e sensibilidade e capacidade para multiplexagem (TEIXEIRA-CARVALHO et al., 2015; OLIVEIRA et al., 2016). Simultaneamente estudos têm avaliado a redução dos níveis de anticorpos em pacientes de LTA após tratamento quimioterápico, esse fato impulsionou o uso da citometria de fluxo para além de diagnosticar, estabelecer um critério de cura (PEREIRA et al., 2012, DE OLIVEIRA et al., 2013).

Diante das perspectivas oferecidas por citometria de fluxo relatado por MartinsFilho et al., (1995), e considerando que o uso de isotipos pode colaborar com uma maior acurácia nos testes (PISSINATE et al., 2008), é importante salientar que a aplicação da citometria de fluxo, para identificar LTA em pacientes antes e após tratamento pode contribuir para a obtenção de um método de maior sensibilidade e especificidade, com aproveitamento diagnóstico e como uma ferramenta para determinar o critério de cura na doença.

\section{MATERIAIS E MÉTODOS}

Foram selecionados 15 pacientes procedentes de Moreno, Zona da Mata de Pernambuco, considerada área endêmica para LTA. Eles eram portadores de lesões ativas, de ambos os sexos e com idade superior a 15 anos. Esses pacientes receberam atendimento no ambulatório do Centro de Pesquisas Aggeu Magalhães (CPqAM), onde ficaram cientes do objetivo do estudo e concordaram em assinar o "Termo de Consentimento Livre e Esclarecido" (TCLE). O material coletado foi processado no Instituto Aggeu Magalhães - FIOCRUZ, na cidade de Recife - PE. Os protocolos 
experimentais foram aprovados pelo Comitê de Ética em Pesquisa do IAM/FIOCRUZ (CAAE 11083812.7.0000.5190). O soro foi obtido após centrifugação em temperatura ambiente, e depois inativado em banho-maria a $57{ }^{\circ} \mathrm{C}$ por 30 minutos. Formas promastigotas de Leishmania $(V$. ) braziliensis foram obtidas a partir da cepa de referência e expandidas em meio Schneider's até atingir a sua fase exponencial. Em seguida, os parasitas foram processados e a concentração ajustada para realização dos ensaios de citometria de fluxo.

\section{RESULTADOS E DISCUSSÃO}

Em relação à padronização do isotipo IgG1, apenas os soros que apresentaram PPFP $>50 \%$ foram considerados positivos. O ponto de corte foi determinado através da construção da curva ROC (Receiver Operating Characteristic Curve), onde cruzamos diferentes valores de sensibilidade e especificidade com diversos pontos de corte e observamos que o ponto de $50 \%$ foi o melhor para o teste de citometria de fluxo.

A reatividade do ensaio de citometria de fluxo foi expressa a partir das diluições testadas do conjugado IgG1 (1:100 a 1:6400), obtidas após incubação com os soros controle positivo $(\mathrm{CP})$ e controle negativo $(\mathrm{CN})$ nas diluições de 1:64 a 1:8192, em condições previamente padronizadas em trabalhos anteriores do grupo, como DE OLIVEIRA et al., 2013. A diluição do conjugado que melhor discriminou os grupos avaliados foi a diluição de 1:400, como descrito na Figura 1.

Figura 1 - Gráfico de avaliação da aplicabilidade do isotipo IgG1.

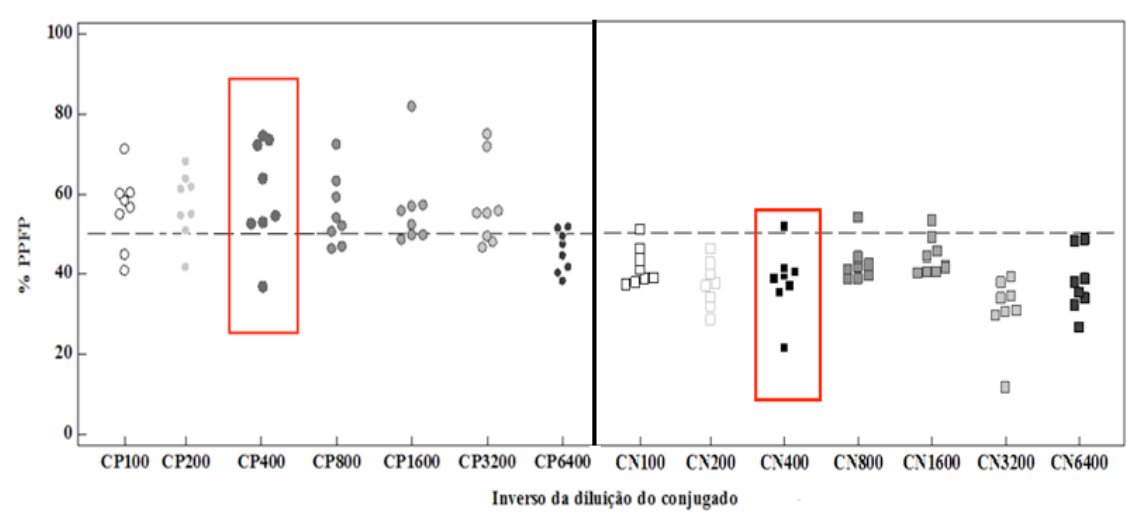

A análise da curva de titulação do anticorpo IgG1 anti-formas promastigotas de $L$. $(V$.) braziliensis presentes em soros dos pacientes controles e expresso por valores de PPFP, sugere que a diluição 1:256 é a região $(\mathrm{R})$ de reatividade, correspondendo ao primeiro título de reação diferencial entre os indivíduos AT, como descrito na Figura 2. 
Figura 2 - Curvas de titulação na diluição 1:400 do isotipo IgG1.

\section{ENCONTRO BRASILEIRO PARA INOVAÇÃO TERAPÊUTICA}

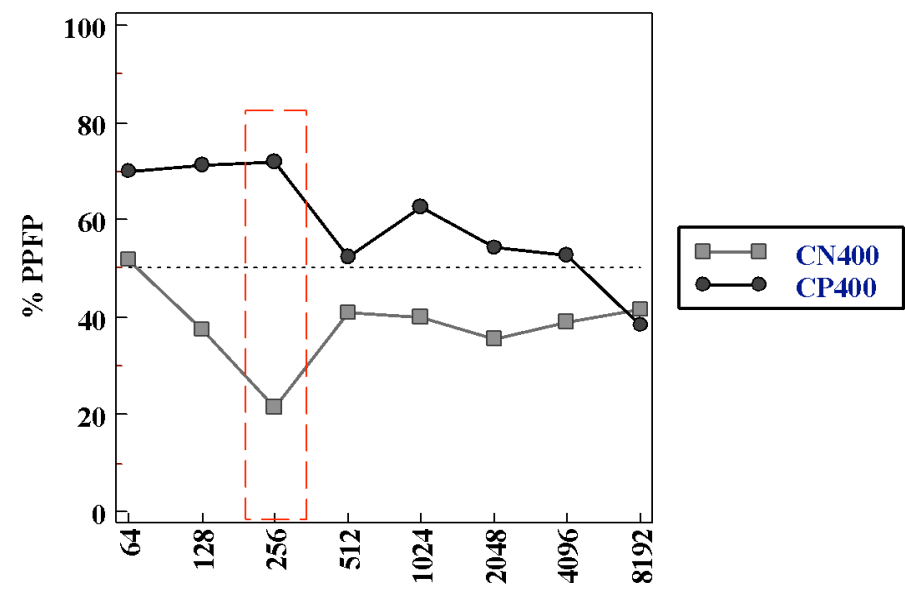

Inverso da diluição do soro

Após a escolha da diluição 1:400 para o conjugado IgG1 anti-formas promastigotas de $L$. (V.) braziliensis, considerando-se a diluição 1:100 do conjugado (PE) e de 1:256 do soro do paciente, foi possível melhor discriminar os pacientes $\mathrm{CP}$ de $\mathrm{CN}$.

Após identificar a região de reatividade e o ponto de corte, prosseguimos com a confirmação da aplicabilidade do isotipo IgG1 na identificação de pacientes positivos e negativos para LTA. Foi possível constatar que, antes do tratamento, 36,8\% dos pacientes se apresentaram negativos. Os resultados dos pacientes com um ano, dois e cinco anos após o tratamento, apresentaram percentuais de negatividade de $82,3 \%, 27,2 \%$ e $87,5 \%$, respectivamente. Estes resultados podem ser observados na Figura 3.

Figura 3 - Avaliação da aplicabilidade do ensaio de citometria de fluxo utilizando o anticorpo IgG1 na identificação de pacientes com LTA ativa.

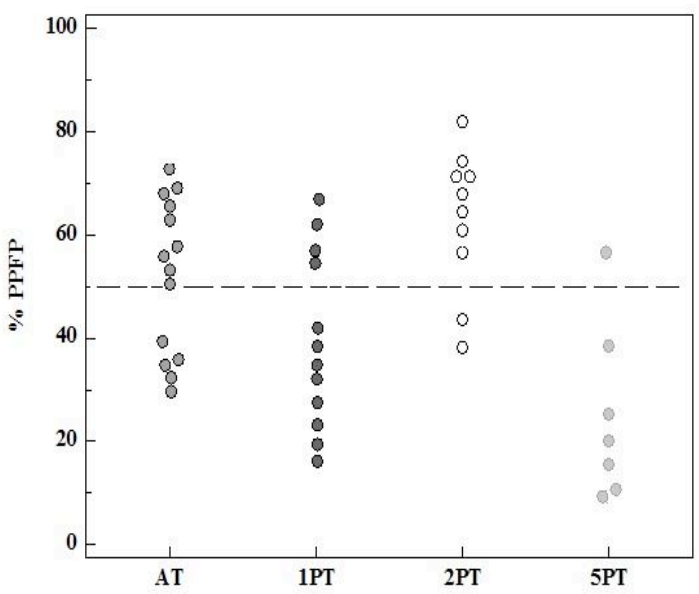

Os resultados obtidos dos ensaios de citometria de fluxo do isotipo IgG1 foram utilizados para construir a curva ROC, avaliando-se a acurácia do teste. A análise da curva ROC mostrou que ASC (Área sob a Curva) foi 0,931 ( IC $\left._{95 \%}=0,698-0,997\right)$. Portanto, o teste obteve um excelente desempenho Figura 4. 
Figura 4 - Curva ROC para o isotipo IgG1.

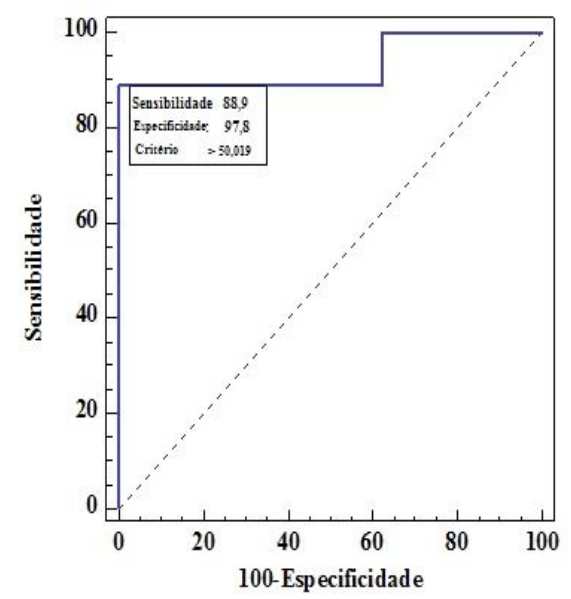

Para padronização do isotipo IgG2, apenas os soros que apresentaram PPFP $>50 \%$ foram considerados positivos. A reatividade do ensaio de citometria de fluxo foi expressa a partir das diluições testadas do conjugado IgG2 (1:100 a 1: 800), obtidas após incubação com os soros CP e CN nas diluições de 1:64 a 1:8192 com promastigotas fixadas nas condições previamente padronizadas. A diluição do conjugado que melhor discriminou os grupos avaliados foi de 1:100, como descrito na figura 5 .

Figura 5 - Gráfico de avaliação da aplicabilidade do isotipo IgG2.

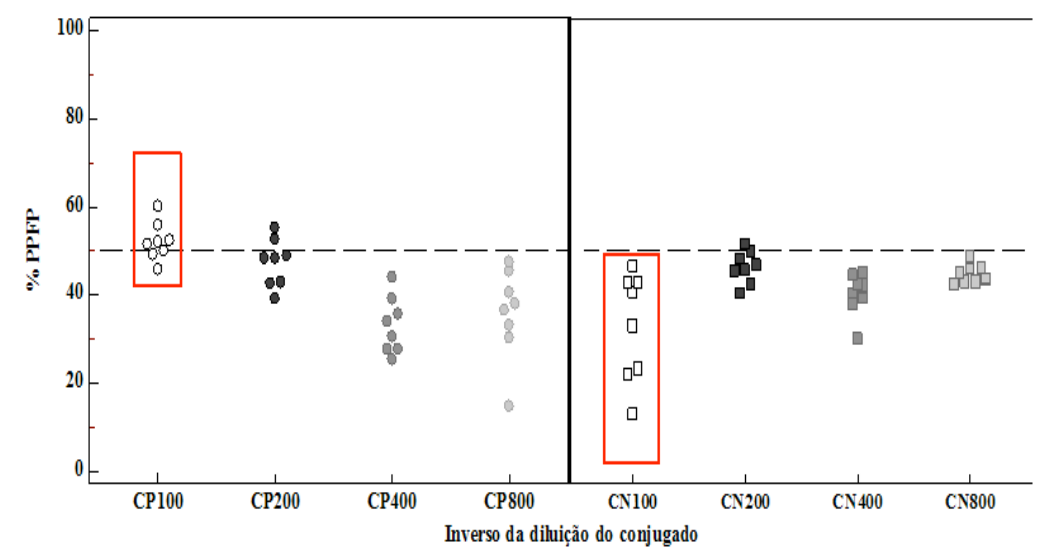

A análise da curva de titulação do anticorpo IgG2 anti-formas promastigotas de L.(V.) braziliensis presentes em soros $\mathrm{CP}$ e $\mathrm{CN}$, expressos com os valores de PPFP, sugerem que a diluição 1:512 é a região $(\mathrm{R})$ de reatividade, correspondendo ao primeiro título de reação diferencial entre os indivíduos AT Figura 6. 
Figura 6 - Curvas de titulação do isotipo IgG2 na sua diluição 1:100.

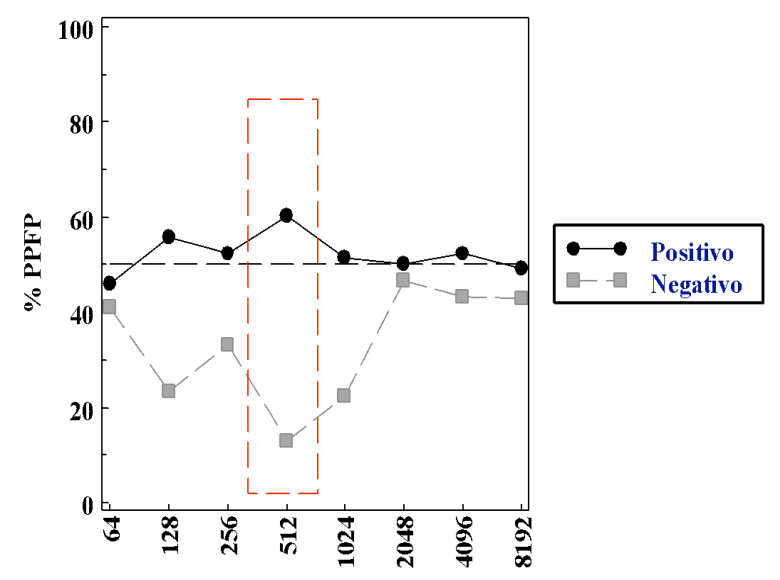

Inverso da diluição do soro

\section{CONCLUSÃO}

Diante dos resultados obtidos é possível sugerir que a citometria de fluxo é aplicável ao diagnóstico da LTA, uma vez que apresentou resultados positivos na presença da doença. Ainda se constatou a possibilidade de utilizar a metodologia como critério de cura, uma vez que foi possível, através do ponto de corte empregado, distinguir pacientes com doença ativa dos curados, embora sejam necessários mais estudos com relação à avaliação da aplicabilidade do isotipo IgG2. Além disso, se faz necessário o aumento do número de amostras para os ensaios do isotipo IgG1 e, dessa forma, aprimorar a avaliação do desempenho do teste. Portanto, é possível sugerir que a utilização desses dois isotipos é aplicável ao diagnóstico da LTA por apresentarem resultados positivos na presença da doença, contribuindo para o alcance de uma técnica mais sensível e específica.

\section{REFERÊNCIAS}

CROFT, S. L.; COOMBS, G. H. Leishmaniasis-current chemotherapy and recent advances in the search for novel drugs. Trends in parasitology, v. 19, n. 11, p. 502-508, 2003.

DE OLIVEIRA, A. P. et al. Comparison of flow cytometry and indirect immunofluorescence assay in the diagnosis and cure criterion after therapy of American tegumentary leishmaniasis by anti-live Leishmania (Viannia) braziliensis immunoglobulin G. J Immunol Methods, v. 387, n. 1-2, p. 245-53, 2013.

GURUNG, P.; KANNEGANTI, T. D. Innate immunity against Leishmania infections. Cellular Microbiology, v. 17, n. 9, p. 1286-1294, 2015.

MARTINS-FILHO, O. A. et al. Cytometry, a New Approach To Detect Anti-Live Trypomastigote Antibodies and Monitor the Efficacy of Specific Treatment in Human Chagas' Disease. Clinical and Diagnostic Laboratory Immunology. v. 5, n.2, p. 569$573,1995$. 
OLIVEIRA, B. C. et al. American Tegumentary Leishmaniasis and Flow Cytometry: A Review. Journal of medical microbiology \& diagnosis, v. 5, p. 1-5, 2016.

PEDRAL- SAMPAIO G. et al. Detection of IgG Anti-Leishmania Antigen by Flow Cytometry as a Diagnostic Test for Cutaneous Leishmaniasis. PloS one, 2016.

PEREIRA, V. R. et al. Evaluation of anti-lived and anti-fixed Leishmania (Viannia) braziliensis promastigote IgG antibodies detected by flow cytometry for diagnosis and post-therapeutic cure assessment in localized cutaneous leishmaniasis. Diagn Microbiol Infect Dis, v. 74, n. 3, p. 292-8, 2012.

PISSINATE, J. F. et al. Upgrading the flow-cytometric analysis of anti-Leishmania immunoglobulins for the diagnosis of American tegumentary leishmaniasis. Journal of immunological methods, v. 336, n. 2, p. 193-202, 2008.

REIS, L. et al. Mecanismos imunológicos na resposta celular e humoral na leishmaniose tegumentar americana. Revista de Patologia Tropical, v. 35, n. 2, p. 103-116, 2007.

ROCHA, R. et al. Clinical value of anti- live Leishmania (Viannia) braziliensis immunoglobulin $\mathrm{G}$ subclasses, detected by flow cytometry, for diagnosing active localized cutaneous leishmaniasis. Tropical Medicine \& International Health, v. 11, n. 2, p. 156-166, 2006.

SOUZA M. A. et al. Perfil de isotipos de imunoglobulinas e subclasses de $\operatorname{IgG}$ na leishmaniose tegumentar americana. Revista da Sociedade Brasileira de Medicina Tropical, 38(2): 137-141, 2005.

SOUSA, S. et al. Development of a fluorescent based immunosensor for the serodiagnosis of canine leishmaniasis combining immunomagnetic separation and flow cytometry. PLoS Negl Trop Dis, v. 7, n. 8, p. e2371, 2013.

TIUMAN, T. S. et al. Recent advances in leishmaniasis treatment. International Journal of Infectious Diseases, v. 15, n. 8, p. e525-e532, 2011.

TEIXEIRA-CARVALHO, A. et al. FC-TRIPLEX Chagas/Leish IgG1: A Multiplexed Flow Cytometry Method for Differential Serological Diagnosis of Chagas Disease and Leishmaniasis. PloS one, v. 10, n. 4, p. e0122938, 2015.

TRUJILLO, C. et al. The humoral immune response to the kinetoplastid membrane protein-11 in patients with American leishmaniasis and Chagas disease: prevalence of IgG subclasses and mapping of epitopes. Immunology letters, v. 70, n. 3, p. 203-209, 2000 .

\section{AGRADECIMENTOS}

CNPq, CAPES, FACEPE, FIOCRUZ, UFPE. 